\title{
The Production of Bioethanol from Cashew Apple Juice by Batch Fermentation Using Saccharomyces cerevisiae Y2084 and Vin13
}

\author{
Evanie Devi Deenanath, ${ }^{1}$ Karl Rumbold, ${ }^{2}$ and Sunny Iyuke ${ }^{1}$ \\ ${ }^{1}$ School of Chemical \& Metallurgical Engineering, University of the Witwatersrand, 1 Jan Smuts Avenue, \\ Braamfontein, Johannesburg 2000, South Africa \\ ${ }^{2}$ School of Molecular \& Cell Biology, University of the Witwatersrand, 1 Jan Smuts Avenue, Braamfontein, \\ Johannesburg 2000, South Africa \\ Correspondence should be addressed to Evanie Devi Deenanath; edeenanath@yahoo.com
}

Received 28 March 2013; Accepted 20 April 2013

Academic Editors: C. Koroneos, F. E. Little, and J. Zhang

Copyright (C) 2013 Evanie Devi Deenanath et al. This is an open access article distributed under the Creative Commons Attribution License, which permits unrestricted use, distribution, and reproduction in any medium, provided the original work is properly cited.

Bioethanol as a fossil fuel additive to decrease environmental pollution and reduce the stress of the decline in crude oil availability is becoming increasingly popular. This study aimed to evaluate the concentration of bioethanol obtainable from fermenting cashew apple juice by the microorganism Saccharomyces cerevisiae Y2084 and Vin13. The fermentation conditions were as follows: initial sugar $=100 \mathrm{~g} / \mathrm{L}, \mathrm{pH}=4.50$, agitation $=150 \mathrm{rpm}$, temperatures $=30^{\circ} \mathrm{C}(\mathrm{Y} 2084)$ and $20^{\circ} \mathrm{C}($ Vin13 $)$, oxygen saturation $=0 \%$ or $50 \%$, and yeast inoculum concentration $=\sim 8.00 \mathrm{Log} \mathrm{CFU} / \mathrm{mL}$. The maximum ethanol concentration achieved by Y2084 was $65.00 \mathrm{~g} / \mathrm{L}$. At $50 \%$ oxygen the fermentation time was 5 days, whilst at $0 \%$ oxygen the fermentation time was 11 days for Y2084. The maximum ethanol concentration achieved by Vin13 was $68.00 \mathrm{~g} / \mathrm{L}$. This concentration was obtained at $50 \%$ oxygen, and the fermentation time was 2 days. At $0 \%$ oxygen, Vin13 produced $31.00 \mathrm{~g} / \mathrm{L}$ of ethanol within 2 days. Both yeast strains produced a higher glycerol concentration at $0 \%$ oxygen. Yeast viability counts showed a decrease at $0 \%$ oxygen and an increase at $50 \%$ oxygen of both yeast stains. Other analyses included measurement of carbon dioxide and oxygen gases, process monitoring of the fermentation conditions, and total organic carbon. Gas analysis showed that carbon dioxide increased in conjunction with ethanol production and oxygen decreased. Process monitoring depicted changes and stability of fermentation parameters during the process. Total organic carbon analysis revealed that aerobic fermentation (50\% oxygen) was a more efficient process as a higher carbon recovery $(95 \%)$ was achieved.

\section{Introduction}

The twenty-first century is plagued by difficulties like the decrease in resources of fossil fuel, rapid rise in greenhouse gas emissions contributing to global warming, and the lack of capability to meet the increasing energy demands. In trying to reduce the impact of these global concerns, bioethanol produced from renewable resources like biomass components has created significant interest. Bioethanol is a biofuel produced from biomass via biochemical procedures [1]. In general, bioethanol production is a three-stage process of: (i) hydrolysis, (ii) fermentation and (iii) distillation [2]. During hydrolysis, starch is converted from biomass feedstocks (cereal grains, lignocellulose, and macroalgae) into fermentable monosaccharide sugars [1-3]. Fermentation is a process which involves a sugar-rich substrate and a microorganism (MO) to bring about a chemical change in a closed aerobic or anaerobic atmosphere. For fermentation, $S$. cerevisiae yeasts are the recommended microorganisms (MOs), for their ability to multiply anaerobically and easily convert sugars [4]. The last phase of bioethanol production is distillation. Distillation is a thermochemical separating process that concentrates ethanol to $95 \%$, depending on the difference in boiling points between substrates during heat application $[1,2]$. This biologically derived product is an ethyl alcohol that can be used as a petroleum alternative or additive 
[5]. The bioethanol properties that allow this type of product to be utilized in the motor fuel industry and its respective advantages are summarized in Table 1.

Biomass feedstocks, namely wheat, barley, sorghum, rice, corn, and sugar cane, are widely accessible for bioethanol production and the processing of these raw materials were proven successful [5, 9-11]. However, the present usage of these materials threatens their availability as important food and feed products [12]. Alternatively, agricultural residues or industrial waste products such as barley straw, barley husks, corn stover, sugar cane bagasse, and switchgrass are used for bioethanol production [13-15]. These residues are largely lignocellulosics and require extensive, time-consuming pretreatment methods [16]. Another attractive agroindustrial waste product, with unrecognized potential as a bioethanol substrate, is cashew apples [12]. Cashew apples grow from the cashew tree (Anacardium occidentale L.), which is a native exotic plant in Brazil $[17,18]$. The largest cashew regions are Brazil, India, Mozambique, Nigeria, Tanzania, GuineaBissau, Indonesia, and Vietnam [17-19]. Cashew apples are a false fruits and are physically described as small, hard, pearshaped green fruit, and when ripened turn red, yellow, or orange [20-22]. Globally, approximately $10 \mathrm{t} / \mathrm{ha}$ to $30 \mathrm{t} / \mathrm{ha}$ of cashew apples are available [19]. In Brazil, yearly harvests produce an estimated 2 million tons of cashew apples, with $90-94 \%$ of the apples discarded, as the primary industrial product is the cashew nuts $[18,19]$. The $10 \%$ of cashew apples used for the commercial production of wine, fruit juice, jam and ice cream is consumed locally, and exports of these products are stagnant [18, 23-25]. Research applications of cashew apples to date include: (i) dextransucrase production as a preservative in the food industry, (ii) antioxidising capability by characterizing alkyl phenol, (iii) comparison of nutritional quality with market consumable fruits, and (iv) production of biosurfactant for the use in oil-water systems [21, 2529]. Cashew apples exploited for bioethanol production are advantageous as they are rich in sugars (50-200 g/L of glucose and fructose), vitamin $\mathrm{C}$, mineral salts, and amino acids which are essential for yeast assimilation and yeast growth. Moreover, the apples are readily available in large quantities when neglected in their cultivation areas after harvesting of the cashew nut $[17-19,21,25]$. In general, the first step of bioethanol production from cashew apples is extraction of cashew apple juice (CAJ). CAJ is then treated with tannase or gelatin powder to eliminate tannins and filtered to eliminate suspended solids $[25,30]$. Pretreated CAJ, which is the fermentation medium, will be with supplemented with ammonium sulphate and sterilized and fermented at $30^{\circ} \mathrm{C}$ using $S$. cerevisiae yeast $[22,31]$. Thus far, research studies have shown that ethanol concentrations ranging from $19.82 \mathrm{~g} / \mathrm{L}$ to $44.40 \mathrm{~g} / \mathrm{L}$ are achievable using CAJ [22, 31].

The purpose of this research study was to investigate the use of CAJ as a fermentation substrate aiming at bioethanol production using a brewers yeast (S. cerevisiae NRRL Y2084) and wine yeast (S. cerevisiae Vin13). Batch experiments were conducted in a BIOSTAT Bplus reactor, used as a fermentation vessel under defined parameters of temperature, $\mathrm{pH}$, and oxygen. The fermentation product was monitored daily by analyzing yeast viability, sugar consumption, ethanol production and glycerol production. In addition, the total organic product of the CAJ and final fermentation product were analyzed. The fermentation parameters were monitored using the MFCS/DA software programmer to generate process data, and carbon dioxide and oxygen gas were analyzed.

\section{Materials and Methods}

\subsection{Raw Materials}

2.1.1. Cashew Apples. The cashew apples used in this study were obtained from the Coastal Cashews plantation during the February 2011 harvest season. The plantation is located along the Coastal Forest Reserve in the rural Manguzi region in Northern KwaZulu Natal, South Africa. A mixed variety of cashew apples that did not show cashew nut attachment were selected from the cashew orchards by the farm manager (Mr. W. Mthembu) at Coastal Cashews.

2.1.2. Microorganisms. Two strains of Saccharomyces (S.) cerevisiae yeasts were the microorganisms used for fermentation. The first strain, namely, S. cerevisiae NRRL Y2084, is a brewers yeast, whilst the second strain, namely, S. cerevisiae Vin13, is a wine yeast. S. cerevisiae NRRL Y2084 was previously isolated and characterized from dry brewer's yeast, purchased from National Food Products (Johannesburg, South Africa) and maintained at $-70^{\circ} \mathrm{C}$ in $50 \%$ glycerol [32]. S. cerevisiae Vin13 is a product of the Wine and Biotechnology Institute (Stellenbosch, South Africa) and was kindly donated by Anchor Wine Yeast (Cape Town, South Africa). In this study, the yeasts were simply referred to as Y2084 and Vin13.

\subsection{Cashew Apple Juice Extraction and Preparation}

2.2.1. Extraction. Cashew apple juice (CAJ) extraction was done at the cashew nut factory on the Coastal Cashew plantation. The whole cashew apples were washed and cut in half. The apple pieces were then compressed in a fruit processor, with a separate pulp collector. Whilst extracting, the CAJ was kept cold on ice and then frozen. During transportation to the University of the Witwatersrand, Johannesburg, the CAJ was maintained frozen in thermal bags and kept on ice. Upon arrival, the CAJ was stored at $-20^{\circ} \mathrm{C}$ for subsequent use.

2.2.2. Preparation. CAJ was prepared, prior to each fermentation by pretreatment, centrifugation and sterilization. Pretreatment involved the addition of $1 \%(\mathrm{w} / \mathrm{v})$ gelatin powder to the raw CAJ and maintained at $4^{\circ} \mathrm{C}$ for $24 \mathrm{hrs}$ [19]. This was followed by centrifugation at $3500 \mathrm{rpm}$ for $20 \mathrm{~min}$, addition of $2.5 \mathrm{~g} / \mathrm{L}$ of ammonium sulphate, and sterilization at $121^{\circ} \mathrm{C}$ for $15 \mathrm{~min}$ [21, 31]. The CAJ was sterilized in conjunction with the fermentation vessel.

2.3. Yeast Inoculum Preparation. Inoculum of the yeast species was prepared in sterilized yeast peptone dextrose (YPD) liquid broth. The composition of YPD in $\mathrm{g} / \mathrm{L}$ was $10 \mathrm{~g}$ yeast extract powder, $20 \mathrm{~g}$ peptone powder and $20 \mathrm{~g}$ D-glucose. The culture conditions were as follows: (i) volume $=200 \mathrm{~mL}$, 
TABLE 1: Bioethanol fuel properties and related advantages as a fuel additive.

\begin{tabular}{|c|c|c|}
\hline Bioethanol fuel property & Advantages & References \\
\hline $\begin{array}{l}\text { High oxygen content } \\
(35 \% \mathrm{w} / \mathrm{w})\end{array}$ & $\begin{array}{l}\text { (i) Increased combustion efficiency } \\
\text { (ii) Reduced hydrocarbon and carbon monoxide emissions }\end{array}$ & $\begin{array}{l}\text { de Menezes et al. [6] } \\
\text { Demirbas [1] } \\
\text { Sánchez and Cardona [4] }\end{array}$ \\
\hline $\begin{array}{l}\text { High octane number (107) and high } \\
\text { latent heat of vaporization }(0.91 \mathrm{MJ} / \mathrm{kg})\end{array}$ & $\begin{array}{l}\text { (i) Prevents premature ignition and cylinder knocking } \\
\text { (ii) Spontaneous ignition in internal combustion engines when } \\
\text { bioethanol petrol blends are used }\end{array}$ & $\begin{array}{l}\text { Demirbas [1] } \\
\text { Turner et al. [7] } \\
\text { Walker [8] }\end{array}$ \\
\hline Low energy content $\left(21.2 \mathrm{MJ} / \mathrm{dm}^{3}\right)$ & $\begin{array}{l}\text { (i) Increased compression ratio } \\
\text { (ii) Decreased burn time } \\
\text { (iii) Increased power }\end{array}$ & $\begin{array}{l}\text { Demirbas [1] } \\
\text { Jegannathan et al. [2] } \\
\text { Walker [8] }\end{array}$ \\
\hline
\end{tabular}

(ii) temperature $=30^{\circ} \mathrm{C}$, (iii) agitation $=150 \mathrm{rpm}$, and (iv) duration $=18 \mathrm{hrs}$. The yeast strain Y2084 was activated by extracting the glycerol and resuspending the pellet in $1 \mathrm{~mL}$ of YPD broth, and this suspension was added to $50 \mathrm{~mL}$ of YPD liquid broth [32]. The cell count was increased by subculturing at $10 \%$ every $18 \mathrm{hrs}$ from $50 \mathrm{~mL}$ to $200 \mathrm{~mL}$ [32]. For the yeast strain Vin13, dry yeast pellets (Anchor Wine Yeast) were added to $200 \mathrm{~mL}$ of YPD liquid broth. After cultivation, the cell viability was determined (described in Section 2.5.1) and $10 \%$ of the initial fermentation volume was used as a starter culture.

2.4. Fermentation of Cashew Apple Juice. A BIOSTAT Bplus $2 \mathrm{~L} \mathrm{MO}-\mathrm{O}_{2}$ fermentor (Sartorius Stedim Systems $\mathrm{GmBH}$, Germany) was used for the fermentation of cashew apple juice to produce bioethanol. The operating conditions of the batch fermentations are summarized in Table 2. Fermentations were performed in duplicate.

2.5. Analytical Methods. During fermentation, sample was extracted periodically every $24 \mathrm{hrs}$ and analyzed for yeast viability, sugar consumption, and ethanol and glycerol production. Gas output signals were recorded and MFCS/DA plots were constructed. In addition, CAJ and the final fermented product were evaluated for total organic carbon. Analysis was performed in triplicate for the batch fermentations. Statistical analysis was performed for the replicates.

2.5.1. Yeast Viability. Yeast cell viability of the starter culture and during fermentation was determined by standard plate counts [33]. From the initial sample, $1 \mathrm{~mL}$ was aliquot into $9 \mathrm{~mL}$ of buffered peptone water $(20 \mathrm{~g} / \mathrm{L})$ and tenfold serial dilution was performed. One hundred microliters of the diluted suspension was spread plate onto malt extract agar $(50 \mathrm{~g} / \mathrm{L})$. The agar plates were incubated at $30^{\circ} \mathrm{C}$ for $24-48 \mathrm{hrs}$ and examined for the growth of colonies. Plates showing between 30-300 colonies were selected and counted. Viability was expressed by calculating the colony forming units per $\mathrm{mL}$ [33].

2.5.2. High Performance Liquid Chromatography. High performance liquid chromatography (HPLC-Agilent Technologies) was used to analyze sugar, ethanol and glycerol concentrations. The HPLC system was the LC 1100 series equipped with a solvent delivery system (quaternary pumps),
TABLE 2: Operating conditions of batch fermentations.

\begin{tabular}{lcccc}
\hline Conditions & Run 1 & Run 2 & Run 3 & Run 4 \\
\hline $\begin{array}{l}\text { Working volume } \\
\text { Yeast strain }\end{array}$ & $1 \mathrm{~L}$ & $1 \mathrm{~L}$ & $1 \mathrm{~L}$ & $1 \mathrm{~L}$ \\
$\begin{array}{l}\text { Inoculum } \\
\text { concentration }\end{array}$ & 8.62 & 8.58 & 8.64 & 8.69 \\
(Log CFU/mL) & & & & \\
Temperature & $30^{\circ} \mathrm{C}$ & $30^{\circ} \mathrm{C}$ & $20^{\circ} \mathrm{C}$ & $20^{\circ} \mathrm{C}$ \\
$\mathrm{pH}$ & 4.5 & 4.5 & 4.5 & 4.5 \\
$\mathrm{pO}_{2}$ & $0 \%$ & $50 \%$ & $0 \%$ & $50 \%$ \\
Stirrer speed & $150 \mathrm{rpm}$ & $150 \mathrm{rpm}$ & $150 \mathrm{rpm}$ & $150 \mathrm{rpm}$ \\
\hline
\end{tabular}

autosampler, refractive index and wavelength detectors, thermostated column compartment, and ChemStation software programme. For the analysis, a refractive index detector (RID) and the Aminex fermentation monitor column (Biorad) were used. HPLC conditions were as follows: (i) mobile phase $=0.001 \mathrm{M}$ sulphuric acid, (ii) flow rate $=0.8 \mathrm{~mL} / \mathrm{min}$, (iii) column temperature $=60^{\circ} \mathrm{C}$, (iv) $\mathrm{RID}$ temperature $=$ $40^{\circ} \mathrm{C}$, (v) injection volume $=20 \mu \mathrm{L}$, and (vi) pressure $=60 \mathrm{bar}$. The ChemStation Software programme was used to monitor the data and concentrations were determined by constructing a calibration curve (ChemStation off-line data analysis) using the following standards: glucose $(2 \% \mathrm{w} / \mathrm{v})$, fructose $(2 \% \mathrm{w} / \mathrm{v})$, maltose $(2 \% \mathrm{w} / \mathrm{v})$, ethanol $(12 \% \mathrm{w} / \mathrm{v})$, and glycerol $(1 \% \mathrm{w} / \mathrm{v})$. Triplicate readings were recorded for batch fermentations. Prior to HPLC analysis, the fermented samples were centrifuged at 5,000 rpm for 60 secs using a microcentrifuge (Eppendorf Minispin Plus, Merck). The supernatants were filtered using a $0.45 \mu \mathrm{m}$ syringe filter tip (Minisart cellulose acetate, Sigma), and a volume of $1 \mathrm{~mL}$ was aliquot into HPLC vials.

2.5.3. Gas Analysis. Carbon dioxide and oxygen signals were measured by the use of BCP-sensors (BluSens GmBH, Germany). The output signals displayed on the BIOSTAT system was recorded and volume were determined as per manufacturers instructions.

2.5.4. MFCS/DA Software. Data monitoring of the fermentation conditions were made possible by the BioPAT MFCS/DA 
programmer. Every $24 \mathrm{hrs}$, plots of the measured variables (Table 2) were constructed.

2.5.5. Total Organic Carbon. The total organic carbon (TOC) of CAJ and the final day fermentation product was determined as described by LaPara et al. [34]. Briefly, $2 \mathrm{~mL}$ of the CAJ sample or fermented product sample was aliquot into $1.5 \mathrm{~mL}$ of digestion solution (2.6 g potassium dichromate, $8.33 \mathrm{~g}$ mercuric sulphate, $42 \mathrm{~mL}$ sulphuric acid, and $208 \mathrm{~mL}$ distilled water) and $3.5 \mathrm{~mL}$ of catalyst solution $(5.06 \mathrm{~g}$ silver sulphate and $500 \mathrm{~mL}$ sulphuric acid). This mixture was digested for $2 \mathrm{hrs}$ at $150^{\circ} \mathrm{C}$ [34], using a heating block (Spectroquant TR320 Merck). Following digestion, the tubes were cooled and the concentration readings at $25-1500 \mathrm{mg} / \mathrm{L}$ and $1500-$ $5000 \mathrm{mg} / \mathrm{L}$ were recorded using a spectrophotometer (Spectroquant Pharo 100 Merck). Experiments were performed in triplicate for batch fermentations.

2.5.6. Statistical Analysis. Statistical analysis was carried out for the following data: HPLC, yeast viability, and TOC results. HPLC and TOC data was statically analyzed for inferential statistics using the software programme STATA 21.1 (StataCorp LP, College Station, Texas 77845, USA). Yeast viable cell counts were analyzed for descriptive statistics using Microsoft Excel 2010. For the inferential statistics, analysis of variance (ANOVA) and significant differences among the means were tested by one-way ANOVA at the 95\% confidence interval. Standard deviation was also reported. The results were declared significant when $P \leq 0.05$. For the descriptive statistics, the mean and standard deviations were reported.

\section{Results and Discussion}

\subsection{Raw Materials}

3.1.1. Cashew Apples. For this research cashew apples were obtained from Coastal Cashews located in the KwaNgwanase region in Northern KwaZulu Natal, South Africa.

During the February 2011 harvest season, cashew apples (CAs) were collected (Figure 1) from the cashew trees at the Coastal Cashew plantation. Figure 1(a) shows a single cashew apple (CA). Figure 1(b) shows a mixed variety of CAs such as red apples, green apples, partial red/yellow to orange apples and even damaged apples (reddish-brown in colour), due to natural falling from the trees. In total, thirty-three kilograms $(33 \mathrm{~kg})$ of CAs were obtained.

3.2. Cashew Apple Juice Preparation. From the $33 \mathrm{~kg}$ of CAs obtained, $8.75 \mathrm{~L}$ of cashew apple juice (CAJ) was extracted. Prior to fermentation CAJ was thawed, centrifuged and pretreated with gelatin powder to remove tannins. The preparation of CAJ was necessary as the clear juice with a lower tannin concentration and minimal to zero suspended solids will allow the yeast to easily assimilate the sugars for growth and the production of ethanol. Furthermore the reduction in tannins, which complexes with gelatin $[25,35]$, will reduce the negative effects on enzyme activity during fermentation as condensed tannins usually form insoluble compounds with proteins [36].

\subsection{Fermentation of Cashew Apple Juice}

3.3.1. Yeast Viability and HPLC Analysis. Figures 2(a)-2(d) depict the comparative analysis of total sugars, ethanol, glycerol, and yeast viability counts of both yeast strains.

HPLC revealed that glucose $(40.56 \mathrm{~g} / \mathrm{L})$ fructose $(57.06 \mathrm{~g} / \mathrm{L})$, and maltose $(2.80 \mathrm{~g} / \mathrm{L})$ are the sugars of CAJ. Both yeast strains exhibit the same patterns of sugar consumption, where glucose was first utilized followed by fructose, irrespective of oxygen saturation (Figure 2(a)). This was expected as Saccharomyces yeast easily assimilates monosaccharides such as glucose and fructose and disaccharides such as maltose [37, 38]. Moreover, these results correspond to the normal pattern of CAJ fermentation [22, 31, 35, 39]. The difference in sugar consumption was that Vin13 showed an affinity for maltose, whereas Y2084 did not (Figure 2(a)) and the residual sugar concentration of run 3 , and run 4 is lower (Figure 2(a)) due to the consumption of maltose by the yeast strain Vin13, and a higher fructose concentration was used. High sugar concentrations can cause osmotic stress to yeast cells $[40,41]$ which is not the case in this study as the yeast strains were able to withstand the sugar concentration of the CAJ. The maximum ethanol concentration produced by Y2084 was $65.17 \mathrm{~g} / \mathrm{L}(F$-value $=21.86 ; P<0.0001)$ for run 1 and $65.12 \mathrm{~g} / \mathrm{L}(F$-value $=13.59 ; P<0.0001)$ for run 2 (Figure $2(\mathrm{~b})$ ). The results are significantly similar. The addition of oxygen did not influence the ethanol concentration, but the fermentation time was affected as the duration of run 1 was 11 days and run 2 was 5 days (Figure 2(b)). Since nitrogen gas was not passed through the system to displace air in the vessel, the fermentation environment of run 1 can be considered as semianaerobic. This is advantageous as the yeast cells were able to survive for a longer time period by acquiring the available air. Additionally, nutritional components from the CAJ, other than sugar and the external supplement of ammonium sulphate, provided support for the growth and functioning of the yeast. For run 3 and run 4 the maximum ethanol concentrations were $31.40 \mathrm{~g} / \mathrm{L}$ $(F$-value $=2.92 ; P=0.0412)$ and $67.74 \mathrm{~g} / \mathrm{L}(F$-value $=10.47$; $P<0.0001$ ), respectively, (Figure 2(b)). The results were significantly different. The addition of oxygen influenced the ethanol concentration, but the fermentation time was unchanged which was 2 days (Figure 2(b)). The yeast strain Y2084 is a slow fermenting yeast compared to Vin13 and requires a longer adaptation period when inoculated into the CAJ substrate. The strain Y2084 has an advantage over Vin13, as in the absence of oxygen Y2084 growth was persistent, and it is likely the strain is able to acquire air, even when the cell numbers are low to sustain growth. The strain Y2084 was isolated from brewers yeast, and these yeasts can easily adapt and grow within stressful conditions [40]. Whereas Vin13 was unable to multiply in the absence of oxygen and based on the results, oxygen is a major contributing factor for Vin13 to achieve a high ethanol concentration (Figure 2(c)). The addition of oxygen during the fermentation provided an aerobic environment for the yeasts and oxygen is known to stimulate the production of unsaturated fatty acids and lipids, which contribute to the maintenance of the cell membrane structure and metabolism during fermentation 


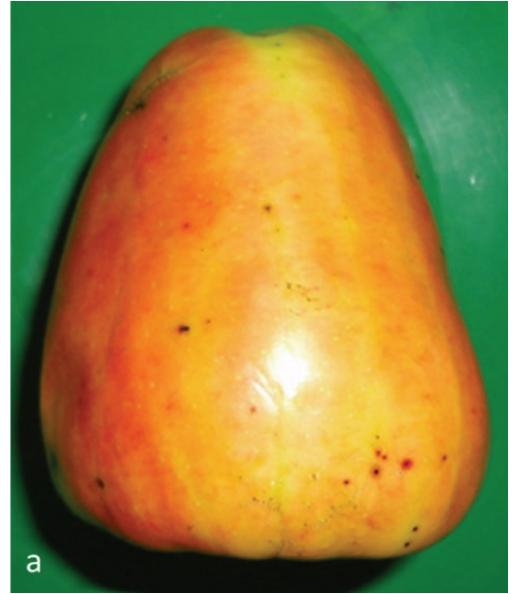

(a)

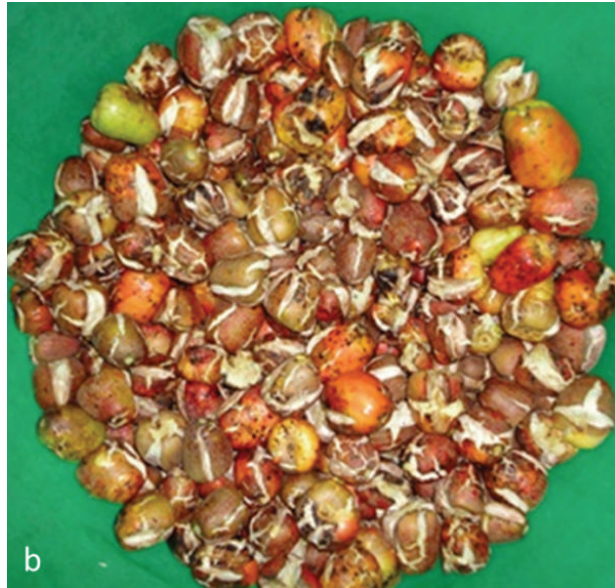

(b)

Figure 1: (a) and (b) pictures showing the cashew apples from the Coastal Cashew plantation in KwaNganase, South Africa.

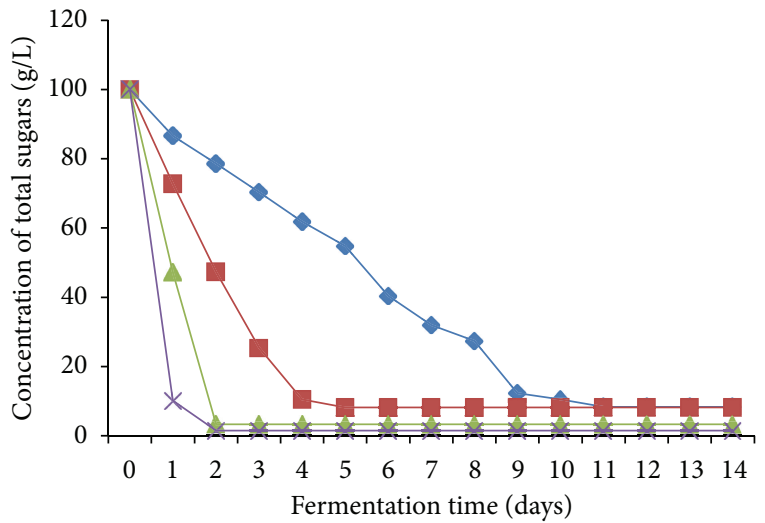

(a)

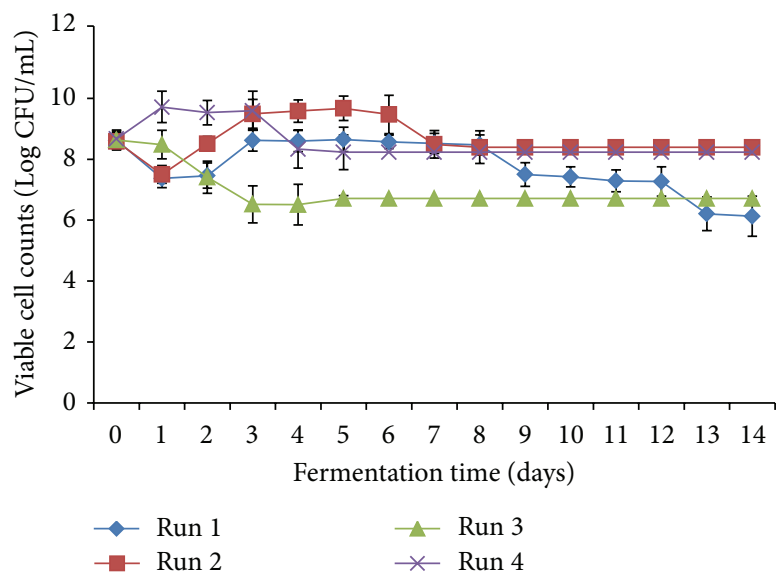

(c)

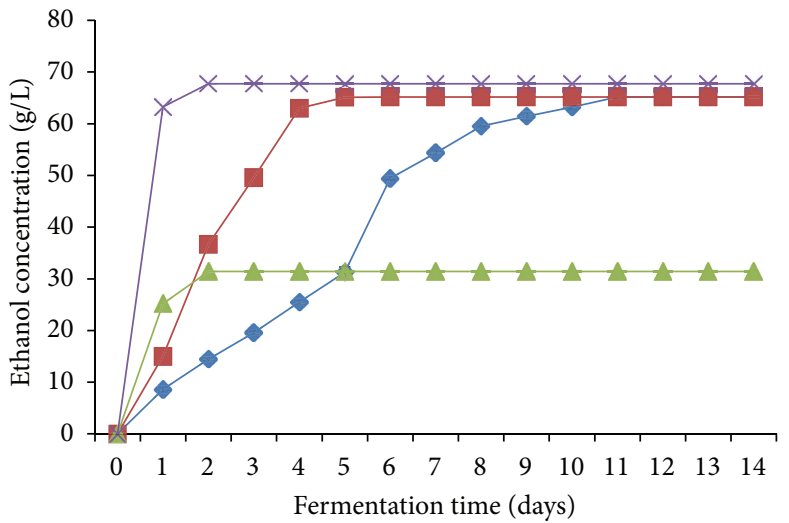

(b)

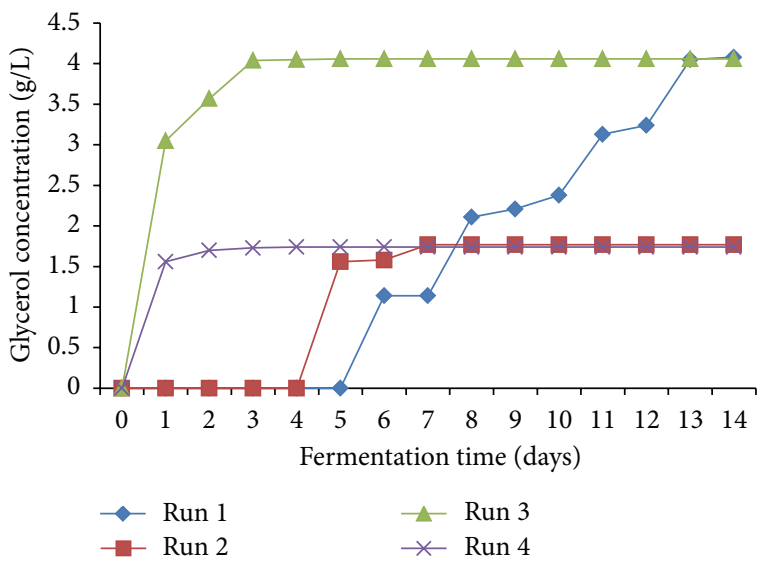

(d)

FIGURE 2: (a)-(d) Comparative fermentation profiles showing the concentration of total sugars (a), ethanol concentration (b), viable cell counts (c), and glycerol concentration (d) of fermentation runs 1, 2, 3, and 4 . The values plotted are an average from six replicates. Error bars represent SD, where not seen, they lie within the symbol. 
[42-47]. Low cell viability in the absence of oxygen is normal as the available lipids are easily exhausted [46]. Viable cell counts show that Y2084 enters a lag phase when introduced into the CAJ (Figure 2(c)). This phase is shorter when the medium is saturated with oxygen like in run 2 (Figure 2(c)). Under semianaerobic, Y2084 progresses from the lag phase to a short exponential phase followed by the stationary phase and eventually enters the death phase (Figure 2(c)). The exponential phase is short lived, and most of the fermentation occurs when the cells are in the stationary phase (Figure 2(c)). Lack of nutrients and possibly oxygen forces the cells into the death phase. Under aerobic conditions, lag phase is short and the Y2084 cells mainly function in exponential phase and enter into the stationary phase (Figure 2(c)). When the ethanol steady state is reached, the cells are in stationary phase (Figures 2(b) and 2(c)). Viable cell counts of Vin13 showed no distinct changes in the growth phases during the course of fermentation (Figure 2(c)) unlike Y2084. Under semianaerobic conditions, the cell viability decreases and the cells remain in the stationary phase (Figure 2(c)). In an aerobic environment, the cells are maintained in the exponential phase (Figure 2(c)). For both yeast strains, the by-product glycerol $[48,49]$ was produced and the concentrations were significantly lower under aerobic conditions (run 2: $P<0.0001$; run 4: $P<0.0001$ ) compared to the semianaerobic conditions (run 1: $P<0.0001$; run 3: $P=0.0412)$. High glycerol concentration is common for anaerobic fermentations [48]. In the semianaerobic environment of run 1 and run 3 the yeast cells released glycerol as a stress response and the glycerol is produced when there is change in enzyme activity from alcohol dehydrogenase to glycerol-3-phosphate dehydrogenase and in order to reoxidize $\mathrm{NAD}^{+}$when oxygen is not available $[31,48]$. Vin13 experienced stress at day 1 and Y2084 at day 6 (Figure 2(d)). The glycerol production is in accordance with sugar depletion and increased ethanol concentrations (Figures 2(a), 2(b), and 2(d)). It is known that high ethanol concentrations greater than $4 \%(\mathrm{v} / \mathrm{v})$ are toxic to yeast and can cause osmotic stress $[35,38,40,50]$. In the current study, toxic-ethanol shock is a possibility under semianaerobic conditions for strain Y2084, as in a related study, it was suggested the accumulation of ethanol was responsible for the decrease in yeast efficiency as the fermentation approached day 15 [35]. For the strain Vin13, stress is most likely due to the lack of oxygen. The low glycerol concentrations of run 2 and run 4 (Figure 2(d)) are due to sugar deprivation and the provided oxygen assists with survival of the cells and the ability to adapt to the stress. The accumulation of glycerol towards the endpoint of fermentation in the current study did not correspond with a previous study [49]. Oxygen saturation has a major effect on both yeast strains as previously mentioned. Other than oxygen, the temperature could also play a role in the fermentation. At a temperature of $30^{\circ} \mathrm{C}$ and oxygen saturation of $0 \%$, the fermentation duration was 11 days, whilst at $50 \%$ saturation, the duration was 5 days. Since oxygen dependence is not an issue for Y2084, based on the significantly similar ethanol concentrations, a temperature change could possibly affect the fermentation time. The ability of Y2084 to ferment at $30^{\circ} \mathrm{C}$ is not unusual as $S$. cerevisiae yeasts can withstand temperatures up to $35^{\circ} \mathrm{C}$ [51]. At a temperature of $20^{\circ} \mathrm{C}$ for run 3 and run 4 , the duration of fermentation was shorter. On the basis of the ethanol results, temperature may or may not influence the concentration as a high ethanol concentration is possible, provided the substrate is saturated with oxygen. Thus, Y2084 can be manipulated at different temperatures to evaluate the effect of fermentation time. For Vin13, different temperatures can be tested to the effect on time and ethanol concentrations, specifically under semianaerobic conditions. From the present data, optimal conditions for $\mathrm{Y} 2084$ are at temperature $30^{\circ} \mathrm{C}$ and $0 \%$ or $50 \%$ oxygen, as the ethanol concentration is high. Optimal conditions for Vin 13 are temperature $20^{\circ} \mathrm{C}$ and $50 \%$ oxygen saturation, as a higher ethanol concentration was obtained. With oxygen saturation, the cells surpassed the initial cell count at the point of inoculation. For run 2 and run 4, cells entered the exponential phase which resulted in faster ethanol production which coincides with the statement by Bellissimi and Ingledew. [52], "that ethanol is produced 30-33 times faster when yeasts are in log phase" [52]. For run 1, the nitrogen from the ammonium supplement and proteins of the CAJ proved useful as Malherbe et al. [45] suggest that nitrogen is necessary to produce proteins that transport sugars for the substrate into the yeast cells [45]. The maximum ethanol produced in the current study for runs 1, 2, and 4 is higher than the value obtained by Pinheiro et al. [31] for bioethanol form CAJ. Fermentation conditions [31] were identical to this study, with the exception of oxygen saturation and the yeast strain. Pinheiro et al. [31] also reported that a higher glycerol concentration and suggested that the production is in response to external osmotic stress furthermore no pretreatment of the CAJ was carried out [31]. From the results of the present study pretreatment to reduce tannins was useful and another contributing factor in obtaining a high ethanol concentration. The reduction of tannins was necessary because these are known to hinder fermentation [53]. Other studies using CAJ as a fermentation substrate for bioethanol production involved the use of immobilized yeast cells $[29,39]$. The result reported by Neelakandan and Usharani [39] was higher than the current reported ethanol concentration. The result reported by Rabelo et al. [29] was lower than the ethanol concentration of runs 1,2 and 4 and similar to the value reported for run 3 . Attri. [35] showed that a higher ethanol concentration than the current study is possible from CAJ using the yeast $S$. cerevisiae var. ellipsoideus, for cashew wine production, and the fermentation time was 15 days [35] which was similar to the time of run 1. From the collective research data, it is confirmed that fermentation conditions and starting sugar concentration are crucial to the outcome of the ethanol concentration with different yeast strains behaving differently under certain conditions, and each $S$. cerevisiae strain is unique.

3.3.2. Gas Analysis. Carbon dioxide $\left(\mathrm{CO}_{2}\right)$ and residual oxygen $\left(\mathrm{O}_{2}\right)$ gas output signals were recorded continuously by the BCP sensors during the course of fermentation. The relationship between the gases and ethanol production is depicted in Figures 3(a)-3(d). 
From Figures 3(a)-3(d), it is evident that ethanol concentration and $\mathrm{CO}_{2}$ volume are in sync and the values converge towards the endpoint of fermentation. For run 1, there is a slow increase, followed by a rapid increase in both $\mathrm{CO}_{2}$ and ethanol (Figure 3(a)). This coincides to the yeast lag phase and the gradual increase in yeast viability and ethanol production as fermentation progresses. At day 6, there is a spike in $\mathrm{CO}_{2}$ (Figure 3(a)), caused by the decline in fructose with an increase in ethanol concentration. The $\mathrm{O}_{2}$ volume is unchanged (Figure 3(a)) as run 1 was carried out at $0 \%$ oxygen. Run 2, similar to run 1 , showed a link between ethanol concentration and $\mathrm{CO}_{2}$ volume (Figure 3(b)). Between day 1 and day 2, the $\mathrm{CO}_{2}$ volume increases as ethanol increases (Figure 3(b)), and yeast cell metabolism is active. From day 3 to day 4 , there is a gradual increase in $\mathrm{CO}_{2}$, and at day 4, steady state is reached (Figure 3(b)). During run 2 , a decrease in the $\mathrm{O}_{2}$ volume is recorded at day 1 and day 2 as the yeast cells enter the exponential phase resulting in an increase in oxygen consumption from the CAJ substrate and a decrease in the volume of total oxygen added (Figure 3(b)). The decline in $\mathrm{O}_{2}$ coincides with yeast growth, $\mathrm{CO}_{2}$ production, and ethanol production (Figure 3(b)). For run 3, the abrupt arrest of the fermentation resulted in a low volume of $\mathrm{CO}_{2}$ (Figure 3(c)). The $\mathrm{O}_{2}$ volume is unchanged (Figure 3(c)), like run 1 . For run 4 , the maximum $\mathrm{CO}_{2}$ volume was recorded at day 1 (Figure $3(\mathrm{~d})$ ). This coincides with the rapid increase in ethanol concentration, oxygen consumption and yeast activity. The $\mathrm{O}_{2}$ volume is similar to run 2; hence the uptake of oxygen by both strains is similar.

Based on the gas analysis there is an agreement between the data, where the $\mathrm{CO}_{2}$ and ethanol increases are in proportion. This is expected because $\mathrm{CO}_{2}$, like ethanol, is released by yeast cells during alcoholic fermentation $[8,54]$. The CAJ is a sufficient substrate for the yeast strains Y2084 and Vin13 as the fermentation follows a normal course where sugar consumption, ethanol production, $\mathrm{CO}_{2}$ production, oxygen consumption and yeast metabolism are in accordance with that.

3.3.3. MFCS/DA Analysis. The software programmer BioPAT MFCS/DA 3.0 was used for the MFCS/DA analysis. This programmer allowed the storage and visualization of the operating conditions as process data of batch fermentations. MFCS/DA data analysis was performed every $24 \mathrm{hrs.} \mathrm{In}$ general, the plots (results not shown) are a visual description of the fermentation process, record input and output setpoint values, show deviations from the setpoint values; realignment of the process on par with the setpoint values is visible. For the fermentation runs 1, 2 and 4 the decrease in $\mathrm{pH}$ was noticeable (plots not shown). The decrease in $\mathrm{pH}$ is normal as most fermentation studies report a decrease in $\mathrm{pH}$ [55-58] which is mainly due to the production of lactic acid or other organic acids [57]. For run 3, an increase in $\mathrm{pH}$ occurred which was probably due to ethanol accumulation. For run 2 and 4 (plots not shown), additional variables such as $\mathrm{pO}_{2}, \mathrm{O} 2$ EN, O2_T, and GASFL were monitored. When the $\mathrm{pO}_{2}$ value drops below the setpoint value (Table 2), regulation of this value is visible by a change in O2_T, O2_EN and GASFL. This is interpreted as follows: when the uptake of
TABLE 3: (a) Carbon percentage (carbon input) of the cashew apple juice. (b) Carbon percentage (carbon output) of fermentation runs $1-4$.

(a)

\begin{tabular}{lc}
\hline Inputs & \% Carbon \\
\hline Total sugars (glucose, fructose, and maltose) & 88.08 \\
Other unidentified compounds & 11.92 \\
\hline Total carbon input & 100 \\
\hline
\end{tabular}

(b)

\begin{tabular}{lcccc}
\hline \multirow{2}{*}{ Outputs } & \multicolumn{4}{c}{ \% Carbon } \\
& Run 1 & Run 2 & Run 3 & Run 4 \\
\hline Residual sugars & 9.31 & 8.82 & 8.00 & 1.70 \\
Ethanol & 72.33 & 70.00 & 74.79 & 76.11 \\
Carbon dioxide & 7.55 & 7.55 & 2.28 & 7.55 \\
Yeasts & 4.46 & 9.02 & 5.93 & 9.62 \\
\hline Total carbon output & 93.65 & 95.39 & 90.72 & 95.00 \\
\hline
\end{tabular}

oxygen occurs, the $\mathrm{pO}_{2}$ value drops and to realign the process and ensure the CAJ medium is saturated at $50 \%$, there is an addition of oxygen, and this value is recorded and displayed as O2_T. Simultaneously, for oxygen addition the valve is opened and closed and denoted by O2_EN. Gas addition is pulse width and the flow rate of the gas is controlled and denoted by GASFL. Other variables such as temperature and stirrer speed were stable throughout the process of runs 1-4.

Based on the MFCS/DA analysis, the potential of the equipment and the in-house control centre of the BIOSTAT Bplus is a capable system for bioethanol production. The ability of the system to ensure that the operating conditions are maintained throughout the fermentation of CAJ coupled with the yeast strains Y2084 and Vin13 is a contributing factor towards obtaining the high concentration of ethanol. Visualization of the stable functioning of the system at small scale is valuable as it enhances the understanding of how the process is controlled on a daily basis and to document the process control. At large scale or industrial scale, fermentation stability among batches might not be possible; thus, this type of data monitoring shows the potential that on par processes are possible.

3.3.4. Total Organic Carbon Analysis. The results of the total organic carbon (TOC) of the CAJ and the fermented CAJ are presented in Tables 3(a) and 3(b), respectively. Table 3(b) displays the TOC results of the final fermentation product of each run as "finished samples may be more consistent in their organic loads" as suggested by Quayle et al. [59].

Carbon output (Table 3(b)) is a representation of the carbon recovery or carbon accounted for after the fermentation process from an initial carbon input of 100\% (Table 3(a)). The highest recovery is reported for runs 1,2 , and 4 and the lowest for run 3 (Table 3(b)). High carbon outputs for run 2 and run 4 were expected because of the high ethanol and yeast concentrations. The carbon output of run 1 is lower than run 2 and run 4 but higher than run 3 (Table 3(b)) as the 


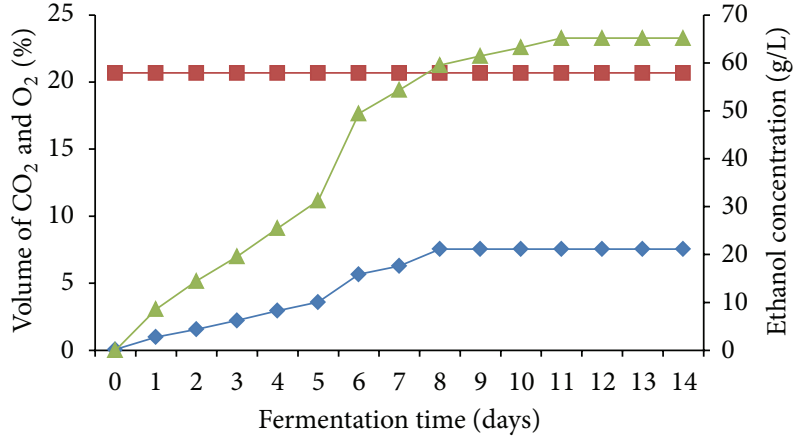

(a)

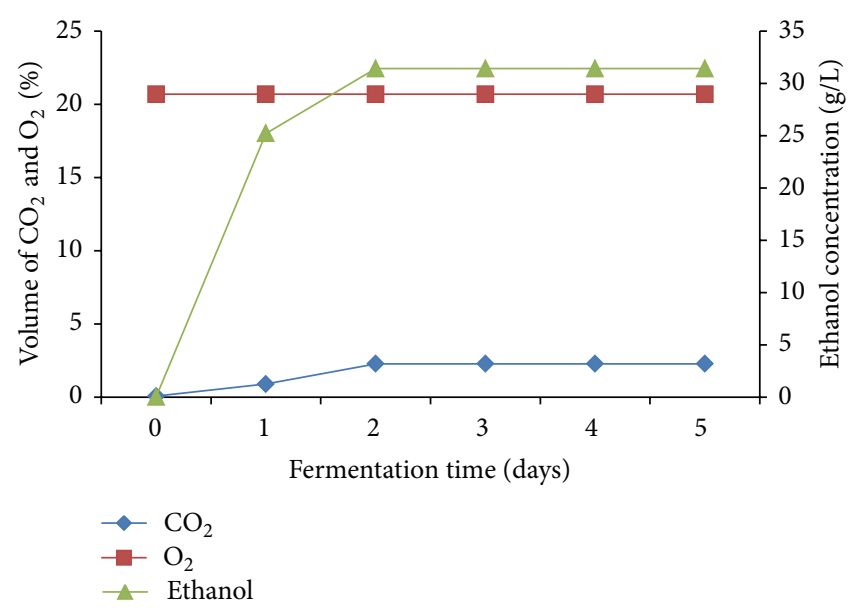

(c)

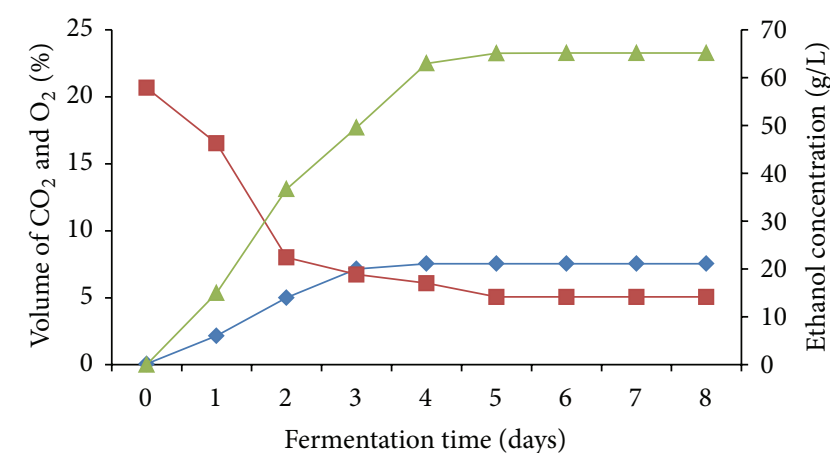

(b)

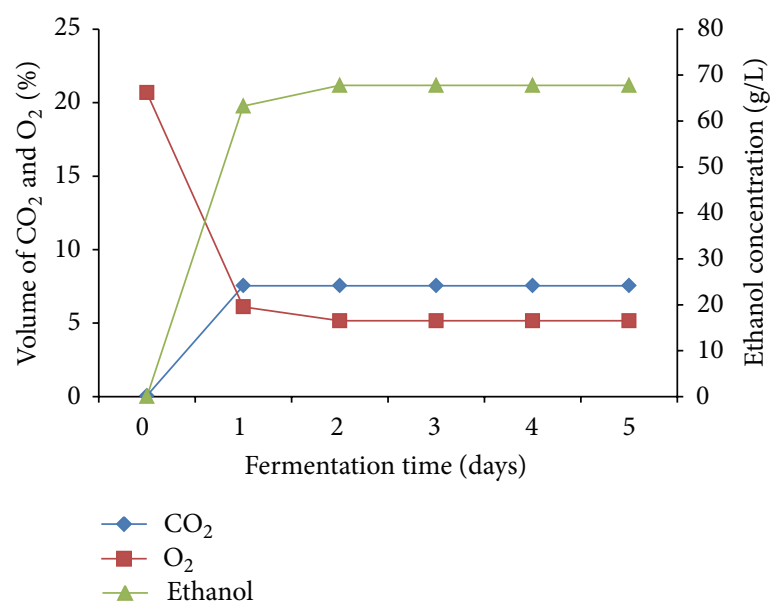

(d)

Figure 3: (a)-(d) Volume of $\mathrm{CO}_{2}$ and $\mathrm{O}_{2}$ to changing ethanol concentrations during the course of fermentation run 1 (a), run 2 (b), run 3 (c), and run $4(\mathrm{~d})$.

ethanol concentration is greater than run 3 and the yeast concentrations are lower than run 2 and run 4 . Limited research is available for TOC and fermented products. A comparison of the TOC results in the present study can be made to a study by J. C. Wang and H. H. Wang [60], the research showed a carbon recovery of $98.60 \%$ and $98.31 \%$ for aerobic and anaerobic fermentation, respectively, is possible from the fermentation of glucose by the bacteria Bacillus cereus [60]. The results in this study are largely different probably because the conversion of sugar by yeast and bacteria during fermentation is different and fermentation conditions could play a role in determining the carbon output.

Based on the TOC analysis, the dominant carbon constituent recovered is ethanol followed by carbon dioxide (Table 3(b)). Thus, the use of CAJ in conjunction with the selected yeast strains is suitable for bioethanol production as the majority of sugars were converted to ethanol. Moreover, the plant performance is efficient under the selected fermentation conditions as greater than $90 \%$ of carbon was recovered with the most efficient processes being run 2 and run 4 as less carbon was lost during the process. Based on the experimental results, the ANOVA analysis demonstrated significance as follows: (i) TOC run 1: $F$-value $=75659.78 ; P$ value $<0.0001$; (ii) TOC run 2: $F$-value $=56109.73 ; P$ value $<$
0.0001; (iii) TOC run 3: $F$-value $=1.3 \mathrm{E}+06 ; P$ value $<0.0001$; (iv) TOC run $4: F$-value $=1.4 \mathrm{E}+05 ; P$ value $<0.0001$. The results were significant.

\section{Conclusion}

In this study, the production of bioethanol by batch fermentation using two types of $S$. cerevisiae yeast strains and cashew apple juice (CAJ) substrate was investigated. The yeast strains Y2084 and Vin13 were used and both strains were able to easily consume and ferment the available sugars of CAJ. Among the strains, Vin13 produced a higher concentration of ethanol and this activity is more efficient in the presence of oxygen. Even though the ethanol concentration achieved by Y2084 was lower, the advantage is, Y2084 is not dependent on oxygen for its activity. Furthermore, other than oxygen the difference in fermentation profiles could be attributed to temperature. The fermentation ability of Y2084 at a higher temperature compared to Vin13 showed a high concentration of bioethanol is possible with respect to selected fermentation conditions even though the duration of the fermentation was longer. Hence, the activity of each yeast strain is unique under specified conditions. The results of this investigation indicated that CAJ is an acceptable substrate, in conjunction 
with yeast strains Y2084 and Vin13 for bioethanol production and as an agricultural waste product can be applied to biotechnology processing to produce a valuable product.

\section{Acknowledgments}

The authors are grateful to the Global Change and Sustainability Research Institute (GCSRI)-WITS Open Society Institute Bursary, DAAD-NRF Joint In-Country Scholarship Programme and IBD Africa Section, and FoodBev SETA Research Grant, for financial support; LABOTEC, South Africa, for supplying the BIOSTAT Bplus system; Mr. S. van Vuuren (Product Manager-LABOTEC), for training and technical assistance; Mr. W. Mthembu (Farm Manager) and Ms. T. Thwala (Project Administrator) at Coastal Cashews for technical assistance; Mr. S. Maphutha (University of the Witwatersrand), for transportation to Coastal Cashews; Anchor Wine Yeast (Cape Town-South Africa), for the kind donation of Vin13 yeast; Dr. C. Yah (School of Health Sciences, University of the Witwatersrand), for assistance with statistical analysis.

\section{References}

[1] A. Demirbas, "Biofuels sources, biofuel policy, biofuel economy and global biofuel projections," Energy Conversion and Management, vol. 49, no. 8, pp. 2106-2116, 2008.

[2] K. R. Jegannathan, E. S. Chan, and P. Ravindra, "Harnessing biofuels: a global Renaissance in energy production?" Renewable and Sustainable Energy Reviews, vol. 13, no. 8, pp. 2163-2168, 2009.

[3] C. S. Goh and K. T. Lee, "A visionary and conceptual macroalgae-based third-generation bioethanol (TGB) biorefinery in Sabah, Malaysia as an underlay for renewable and sustainable development," Renewable and Sustainable Energy Reviews, vol. 14, no. 2, pp. 842-848, 2010.

[4] Ó. J. Sánchez and C. A. Cardona, "Trends in biotechnological production of fuel ethanol from different feedstocks," Bioresource Technology, vol. 99, no. 13, pp. 5270-5295, 2008.

[5] B. Amigun, R. Sigamoney, and H. von Blottnitz, "Commercialisation of biofuel industry in Africa: a review," Renewable and Sustainable Energy Reviews, vol. 12, no. 3, pp. 690-711, 2008.

[6] E. W. de Menezes, R. Cataluña, D. Samios, and R. D. Silva, "Addition of an azeotropic ETBE/ethanol mixture in eurosupertype gasolines," Fuel, vol. 85, no. 17-18, pp. 2567-2577, 2006.

[7] D. Turner, H. Xu, R. F. Cracknell, V. Natarajan, and X. Chen, "Combustion performance of bio-ethanol at various blend ratios in a gasoline direct injection engine," Fuel, vol. 90, no. 5, pp. 1999-2006, 2011.

[8] G. M. Walker, "Fuel ethanol: current production and future challenges," Journal of the Institute of Brewing, vol. 117, no. 1, pp. 3-22, 2011.

[9] S. Kim and B. E. Dale, "Global potential bioethanol production from wasted crops and crop residues," Biomass and Bioenergy, vol. 26, no. 4, pp. 361-375, 2004.

[10] M. Linde, M. Galbe, and G. Zacchi, "Bioethanol production from non-starch carbohydrate residues in process streams from a dry-mill ethanol plant," Bioresource Technology, vol. 99, no. 14, pp. 6505-6511, 2008.
[11] M. Balat and H. Balat, "Recent trends in global production and utilization of bio-ethanol fuel," Applied Energy, vol. 86, no. 11, pp. 2273-2282, 2009.

[12] E. D. Deenanath, S. Iyuke, and K. Rumbold, “The bioethanol industry in Sub-Saharan Africa: history, challenges, and prospects," Journal of Biomedicine and Biotechnology, vol. 2012, Article ID 416491, 11 pages, 2012.

[13] M. Linde, M. Galbe, and G. Zacchi, "Steam pretreatment of acid-sprayed and acid-soaked barley straw for production of ethanol," Applied Biochemistry and Biotechnology, vol. 130, no. 1-3, pp. 546-562, 2006.

[14] M. Linde, M. Galbe, and G. Zacchi, "Simultaneous saccharification and fermentation of steam-pretreated barley straw at low enzyme loadings and low yeast concentration," Enzyme and Microbial Technology, vol. 40, no. 5, pp. 1100-1107, 2007.

[15] G. Najafi, B. Ghobadian, T. Tavakoli, and T. Yusaf, "Potential of bioethanol production from agricultural wastes in Iran," Renewable and Sustainable Energy Reviews, vol. 13, no. 6-7, pp. 1418-1427, 2009.

[16] Y. Sun and J. Cheng, "Hydrolysis of lignocellulosic material for ethanol production: a review, Bioresource Technology, vol. 83, no. 1, pp. 1-11, 2002.

[17] T. L. Honorato, M. C. Rabelo, L. R. B. Gonçalves, G. A. S. Pinto, and S. Rodrigues, "Fermentation of cashew apple juice to produce high added value products," World Journal of Microbiology and Biotechnology, vol. 23, no. 10, pp. 1409-1415, 2007.

[18] D. A. Luz, A. K. O. Rodrigues, F. R. C. Silva et al., "Adsorptive separation of fructose and glucose from an agroindustrial waste of cashew industry," Bioresource Technology, vol. 99, no. 7, pp. 2455-2465, 2008.

[19] M. S. Silveira, C. P. M. L. Fontes, A. A. Guilherme, F. A. N. Fernandes, and S. Rodrigues, "Cashew apple juice as substrate for lactic acid production," Food and Bioprocess Technology, vol. 5, no. 3, pp. 947-953, 2012.

[20] A. J. MacLeod and N. G. de Troconis, "Volatile flavour components of cashew "apple" (Anacardium occidentale)," Phytochemistry, vol. 21, no. 10, pp. 2527-2530, 1982.

[21] M. V. P. Rocha, A. H. S. Oliveira, M. C. M. Souza, and L. R. B. Gonçalves, "Natural cashew apple juice as fermentation medium for biosurfactant production by Acinetobacter calcoaceticus," World Journal of Microbiology and Biotechnology, vol. 22, no. 12, pp. 1295-1299, 2006.

[22] A. M. Pacheco, D. R. Gondim, and L. R. B. Goncalves, "Ethanol production by fermentation using immobilized yeast cells," Applied Biochemistry and Biotechnology, vol. 161, no. 1-8, pp. 209-217, 2010.

[23] A. Osho, "Ethanol and sugar tolerance of wine yeasts isolated from fermenting cashew apple juice," African Journal of Biotechnology, vol. 4, no. 7, pp. 660-662, 2005.

[24] C. D. Rakopoulos, K. A. Antonopoulos, D. C. Rakopoulos, D. T. Hountalas, and E. G. Giakoumis, "Comparative performance and emissions study of a direct injection Diesel engine using blends of Diesel fuel with vegetable oils or bio-diesels of various origins," Energy Conversion and Management, vol. 47, no. 18-19, pp. 3272-3287, 2006.

[25] T. L. Honorato and S. Rodrigues, "Dextransucrase stability in cashew apple juice," Food and Bioprocess Technology, vol. 3, no. 1, pp. 105-110, 2010.

[26] T. O. Akinwale, "Cashew apple juice: its use in fortifying the nutritional quality of some tropical fruits," The European Food Research and Technology, vol. 211, no. 3, pp. 205-207, 2000. 
[27] M. T. S. Trevisan, B. Pfundstein, R. Haubner et al., "Characterization of alkyl phenols in cashew (Anacardium occidentale) products and assay of their antioxidant capacity," Food and Chemical Toxicology, vol. 44, no. 2, pp. 188-197, 2006.

[28] C. M. A. Chagas, T. L. Honorato, G. A. S. Pinto, G. A. Maia, and S. Rodrigues, "Dextransucrase production using cashew apple juice as substrate: effect of phosphate and yeast extract addition," Bioprocess and Biosystems Engineering, vol. 30, no. 3, pp. 207-215, 2007.

[29] M. C. Rabelo, C. P. M. L. Fontes, and S. Rodrigues, "Enzyme synthesis of oligosaccharides using cashew apple juice as substrate," Bioresource Technology, vol. 100, no. 23, pp. 5574-5580, 2009.

[30] D. C. P. Campos, A. S. Santos, D. B. Wolkoff, V. M. Matta, L. M. C. Cabral, and S. Couri, "Cashew apple juice stabilization by microfiltration," Desalination, vol. 148, no. 1-3, pp. 61-65, 2002.

[31] A. D. T. Pinheiro, M. V. P. Rocha, G. R. MacEdo, and L. R. B. Gonçalves, "Evaluation of cashew apple juice for the production of fuel ethanol," Applied Biochemistry and Biotechnology, vol. 148, no. 1-3, pp. 227-234, 2008.

[32] E. D. Deenanath, S. E. Iyuke, and D. Lindsay, "Enzymatic hydrolysis of bitter sorghum for bioethanol production," Master Brewers Association of the Americas-MBAA TQ, 2010.

[33] T. L. Pattison, I. Geornaras, and A. von Holy, "Microbial populations associated with commercially produced South African sorghum beer as determined by conventional and Petrifilm $\AA$ plating," International Journal of Food Microbiology, vol. 43, no. 1-2, pp. 115-122, 1998.

[34] T. M. Lapara, J. E. Alleman, and P. G. Pope, "Miniaturized closed reflux, colorimetric method for the determination of chemical oxygen demand," Waste Management, vol. 20, no. 4, pp. 295298, 2000.

[35] B. L. Attri, "Effect of initial sugar concentration on the physicchemical characteristics and sensory qualities of cashew apple wine," Natural Product Radiance, vol. 8, no. 4, pp. 374-379, 2009.

[36] S. Boyes, P. Strübi, and H. Dawes, "Measurement of protein content in fruit juices, wine and plant extracts in the presence of endogenous organic compounds," LWT-Food Science and Technology, vol. 30, no. 8, pp. 778-785, 1997.

[37] A. J. A. van Maris, A. A. Winkler, M. Kuyper, W. T. A. M. de Laat, J. P. van Dijken, and J. T. Pronk, "Development of efficient xylose fermentation in saccharomyces cerevisiae: xylose isomerase as a key component," Advances in Biochemical Engineering/Biotechnology, vol. 108, pp. 179-204, 2007.

[38] W. H. van Zyl, L. R. Lynd, R. den Haan, and J. E. McBride, "Consolidated bioprocessing for bioethanol production using saccharomyces cerevisiae," Advances in Biochemical Engineering/Biotechnology, vol. 108, pp. 205-235, 2007.

[39] T. Neelakandan and G. Usharani, "Optimization and production of bioethanol from cashew apple juice using immobilized yeast cells by Saccharomyces cerevisiae," America-Eurasian Journal of Scientific Research, vol. 4, no. 2, pp. 85-88, 2009.

[40] M. P. Brosnan, D. Donnelly, T. C. James, and U. Bond, "The stress response is repressed during fermentation in brewery strains of yeast," Journal of Applied Microbiology, vol. 88, no. 5, pp. 746-755, 2000.

[41] S. Gutt and G. Gutt, "Factors influencing the fermentation process and ethanol yield," Romanian Biotechnological Letters, vol. 14, no. 5, pp. 4648-4657, 2009.

[42] S. Kura, H. Nishiumi, and Y. Kawase, "Oxygen transfer in a stirred loop fermentor with dilute polymer solutions," Bioprocess Engineering, vol. 8, no. 5-6, pp. 223-228, 1993.
[43] C. Fornairon-Bonnefond, E. Aguera, C. Deytieux, J. M. Sablayrolles, and J. M. Salmon, "Impact of oxygen addition during enological fermentation on sterol contents in yeast lees and their reactivity towards oxygen," Journal of Bioscience and Bioengineering, vol. 95, no. 5, pp. 496-503, 2003.

[44] J. M. Salmon, "Interactions between yeast, oxygen and polyphenols during alcoholic fermentations: practical implications," LWT_Food Science and Technology, vol. 39, no. 9, pp. 959-965, 2006.

[45] S. Malherbe, F. F. Bauer, and M. du Toit, "Understanding problem fermentations-a review," South African Journal of Enology and Viticulture, vol. 28, no. 2, pp. 169-186, 2007.

[46] I. Mannazzu, D. Angelozzi, S. Belviso et al., "Behaviour of Saccharomyces cerevisiae wine strains during adaptation to unfavourable conditions of fermentation on synthetic medium: cell lipid composition, membrane integrity, viability and fermentative activity," International Journal of Food Microbiology, vol. 121, no. 1, pp. 84-91, 2008.

[47] E. Gómez-Plaza and M. Cano-López, "A review on microoxygenation of red wines: claims, benefits and the underlying chemistry," Food Chemistry, vol. 125, no. 4, pp. 1131-1140, 2011.

[48] M. Ciani, L. Ferraro, and F. Fatichenti, "Influence of glycerol production on the aerobic and anaerobic growth of the wine yeast Candida stellata," Enzyme and Microbial Technology, vol. 27, no. 9, pp. 698-703, 2000.

[49] S. Alfenore, C. Molina-Jouve, S. E. Guillouet, J. L. Uribelarrea, G. Goma, and L. Benbadis, "Improving ethanol production and viability of Saccharomyces cerevisiae by a vitamin feeding strategy during fed-batch process," Applied Microbiology and Biotechnology, vol. 60, no. 1-2, pp. 67-72, 2002.

[50] A. I. El-Diwany, M. S. El-Abyad, A. H. El-Refai, L. A. Sallam, and R. F. Allam, "Effect of some fermentation parameters on ethanol production from beet molasses by Saccharomyces cerevisiae Y7," Bioresource Technology, vol. 42, no. 3, pp. 191-195, 1992.

[51] Z. Kádár, Z. Szengyel, and K. Réczey, "Simultaneous saccharification and fermentation (SSF) of industrial wastes for the production of ethanol," Industrial Crops and Products, vol. 20, no. 1, pp. 103-110, 2004.

[52] E. Bellissimi and W. M. Ingledew, "Metabolic acclimatization: preparing active dry yeast for fuel ethanol production," Process Biochemistry, vol. 40, no. 6, pp. 2205-2213, 2005.

[53] K. G. Duodu, J. R. N. Taylor, P. S. Belton, and B. R. Hamaker, "Factors affecting sorghum protein digestibility," Journal of Cereal Science, vol. 38, no. 2, pp. 117-131, 2003.

[54] J. Piškur, E. Rozpedowska, S. Polakova, A. Merico, and C. Compagno, "How did Saccharomyces evolve to become a good brewer?” Trends in Genetics, vol. 22, no. 4, pp. 183-186, 2006.

[55] T. O. Akinwale, "Fermentation and post fermentation chances in cashew wine," The Journal of Food Technology in Africa, vol. 4, no. 3, pp. 100-102, 1999.

[56] C. S. Yah and S. E. Iyuke, "Monitoring barley extract utilization by Saccharomyces cerevisiae in a Microbrewery," Master Brewers Association of the Americas-MBAA TQ, 2010.

[57] S. M. Araujo, C. F. Silva, J. J. S. Moreira, N. Narain, and R. R. Souza, "Biotechnological process for obtaining new fermented products from cashew apple fruit by Saccharomyces cerevisiae strains," Journal of Industrial Microbiology Biotechnology, vol. 38, no. 9, pp. 1161-1169, 2011.

[58] L. V. A. Reddy and O. V. S. Reddy, "Effect of fermentation conditions on yeast growth and volatile composition of wine produced from mango (Magnifera indica L.) fruit juice," Food and Bioproducts Processing, vol. 89, no. 4, pp. 487-491, 2011. 
[59] W. C. Quayle, A. Fattore, R. Zandona, E. W. Christen, and M. Arienzo, "Evaluation of organic matter concentration in winery wastewater: a case study from Australia," Water Science and Technology, vol. 60, no. 10, pp. 2521-2528, 2009.

[60] J. C. Wang and H. H. Wang, "Fermentation products and carbon balance of spoilage Bacillus cereus," Journal of Food and Drug Analysis, vol. 10, no. 1, pp. 64-68, 2002. 


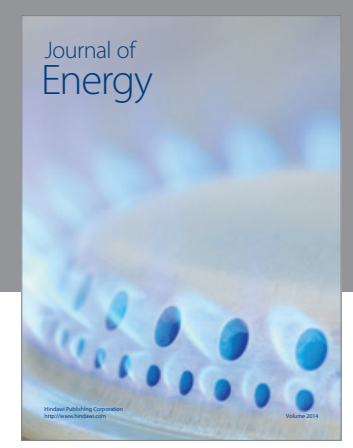

Journal of

Industrial Engineering
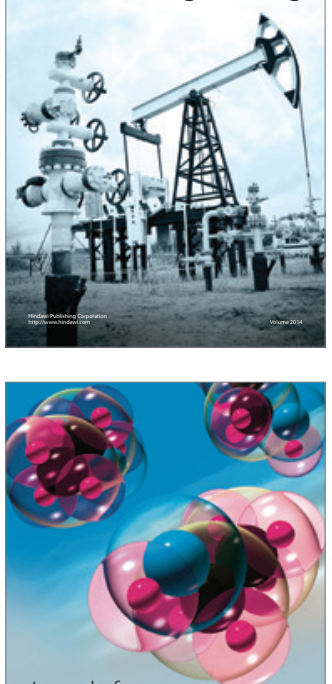

Fuels
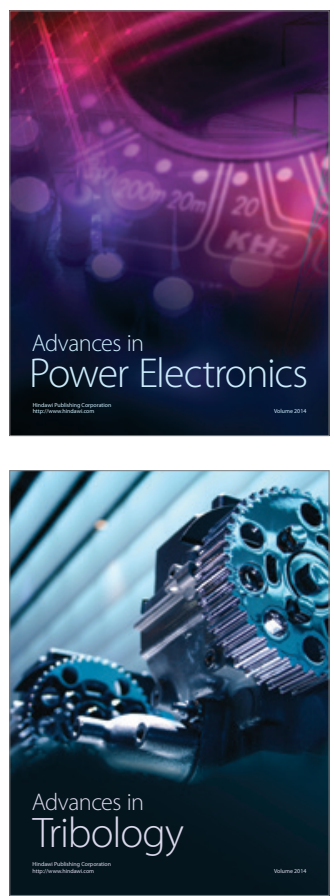

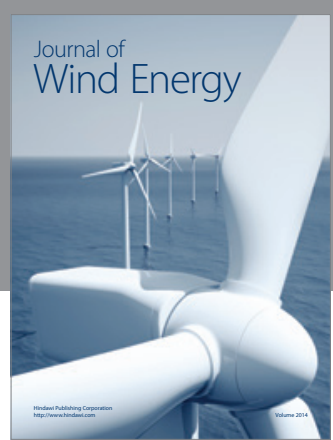

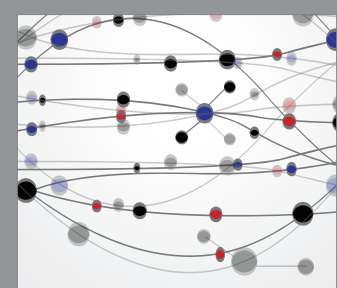

The Scientific World Journal

Submit your manuscripts at http://www.hindawi.com

Journal of

Structures
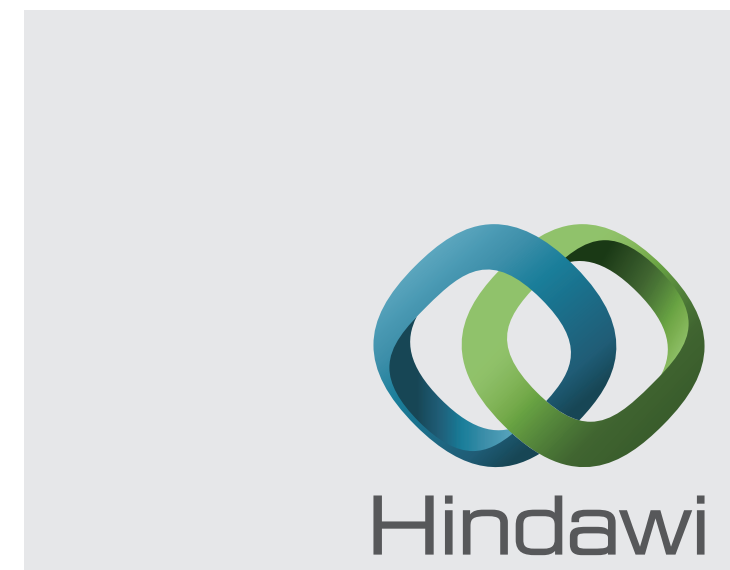

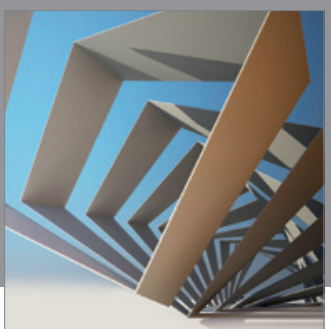

Rotating

Machinery
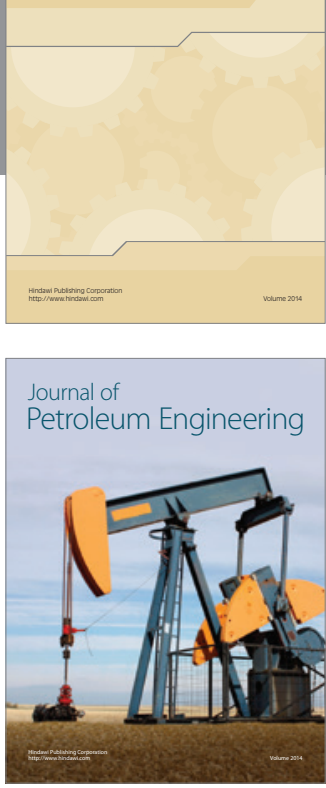

Journal of

Solar Energy
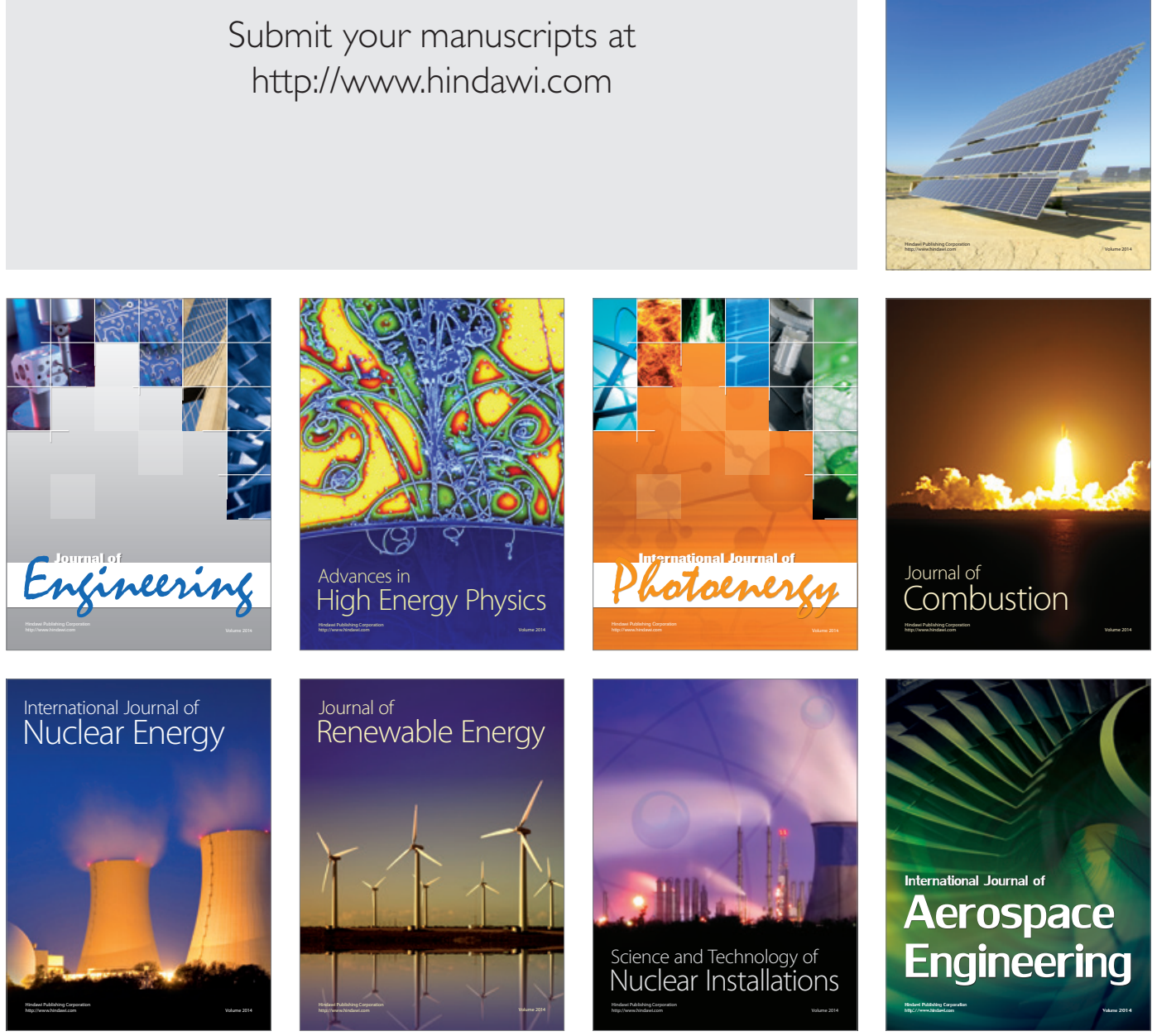